\title{
Mechanical ventilation affects inflammatory mediators in patients undergoing cardiopulmonary bypass for cardiac surgery: A randomized clinical trial
}

\author{
Enrico Zupancich, MD, ${ }^{a} \dagger \ddagger$ Domenico Paparella, MD, ${ }^{\mathrm{b} *} \ddagger$ Franco Turani, MD, ${ }^{\mathrm{a}, \mathrm{c}}$ Christopher Munch, MD, ${ }^{\mathrm{a}}$
} Alessandra Rossi, MD, ${ }^{\text {a }}$ Simone Massaccesi, MD, ${ }^{a}$ and V. Marco Ranieri, MD ${ }^{\mathrm{b}}$

From Servizio di Anestesia e Rianimazione, ${ }^{\mathrm{a}}$ Azienda Ospedaliera Cardiologico "G.M. Lancisi," Ancona, Italy; Anestesiologia e Rianimazione, Dipartimento di Discipline Medico-Chirurgiche, ${ }^{\mathrm{b}}$ Università di Torino, Ospedale S. Giovanni Battista, Turin, Italy; and Anestesia e Rianimazione, ${ }^{\text {c II Univer- }}$ sità degli Studi di Roma "Tor Vergata," Rome, Italy.

This study was supported by a grant from the Italian Minister of University and Reasearch (02-02548) and from the National Research Council (99-9854).

Received for publication June 18, 2004; revisions received Nov 27, 2004; accepted for publication Nov 30, 2004.

Address for reprints: V. Marco Ranieri, MD, Università di Torino, Dipartimento di Discipline Medico-Chirurgiche, Sezione di Anestesiologia e Rianimazione, Ospedale S. Giovanni Battista, Corso Dogliotti 14, 10126 Torino, Italy (E-mail: marco.ranieri@ unito.it)

*Domenico Paparella is currently affiliated with Sezione di Cardiochirurgia, Dipartimento dell'Emergenza e dei Trapianti d'Organo, Università di Bari, Bari, Italy.

$\dagger$ Deceased in April 2001.

$\ddagger$ Drs Zupancich and Paparella equally contributed and should be therefore both considered as first authors of this study.

J Thorac Cardiovasc Surg 2005;130:378-83 $0022-5223 / \$ 30.00$

Copyright (C) 2005 by The American Association for Thoracic Surgery

doi:10.1016/j.jtcvs.2004.11.061
Objectives: Respiratory support for patients recovering from cardiopulmonary bypass and cardiac surgery uses large tidal volumes and a minimal level of positive end-expiratory pressure. Recent data indicate that these ventilator settings might cause pulmonary and systemic inflammation in patients with acute lung injury. We examined the hypothesis that high tidal volumes and low levels of positive endexpiratory pressure might worsen the inflammatory response associated to cardiopulmonary bypass.

Methods: Forty patients undergoing elective coronary artery bypass were randomized to be ventilated after cardiopulmonary bypass disconnection with high tidal volume/low positive end-expiratory pressure $\left(10-12 \mathrm{~mL} / \mathrm{kg}\right.$ and $2-3 \mathrm{~cm} \mathrm{H}_{2} \mathrm{O}$, respectively) or low tidal volume/high positive end-expiratory pressure $(8 \mathrm{~mL} / \mathrm{kg}$ and $10 \mathrm{~cm} \mathrm{H}_{2} \mathrm{O}$, respectively). Interleukin 6 and interleukin 8 levels were measured in the bronchoalveolar lavage fluid and plasma. Samples were taken before sternotomy (time 0 ), immediately after cardiopulmonary bypass separation (time 1 ), and after 6 hours of mechanical ventilation (time 2).

Results: Interleukin 6 and interleukin 8 levels in the bronchoalveolar lavage fluid and plasma significantly increased at time 1 in both groups but further increased at time 2 only in patients ventilated with high tidal volume/low positive end-expiratory pressure. Interleukin 6 and interleukin 8 levels in the bronchoalveolar lavage fluid and in the plasma at time 2 were higher with high tidal volume/low positive end-expiratory pressure than with low tidal volume/high positive end-expiratory pressure.

Conclusion: Mechanical ventilation might be a cofactor able to influence the inflammatory response after cardiac surgery.

$\mathrm{C}$ ardiopulmonary bypass (CPB) is associated with a pulmonary and systemic inflammatory reaction. Although often innocuous, such an inflammatory response might contribute to postoperative complications, including acute lung injury, bleeding disorders, and multiple organ failure. ${ }^{1}$

Despite a widespread use of fast-track protocols, patients might still require several hours of ventilatory support to recover from cardiac surgery. Traditional respiratory support uses a large $(10-15 \mathrm{~mL} / \mathrm{kg})$ tidal volume $\left(\mathrm{V}_{\mathrm{T}}\right)$ to minimize atelectasis, and the minimal level of positive end-expiratory pressure (PEEP) that improves arterial oxygenation by using low inspiratory oxygen fractions with no hemodynamic consequences. ${ }^{2}$ Recent experimental data indicate that these ventilator settings might worsen pulmonary damage with granulocyte activation, hyaline membrane formation, increased vascular permeability, and pulmonary and systemic release of inflammatory mediators. ${ }^{3,4}$ Three recent randomized controlled clinical trials confirmed these experimental findings, showing that in patients with acute 
lung injury, the use of a low $\mathrm{V}_{\mathrm{T}}$ decreased the pulmonary and systemic inflammatory response and improved survival. ${ }^{5-7}$ Whether high PEEP should be associated with low $\mathrm{V}_{\mathrm{T}}$ in these patients is still a matter of debate. ${ }^{8}$

We studied the influence of mechanical ventilation on pulmonary and systemic concentration of inflammatory mediators in patients undergoing CPB for cardiac surgery. This study examines the hypothesis that mechanical ventilation with a high $\mathrm{V}_{\mathrm{T}}$ and low levels of PEEP might further increase the concentration of inflammatory mediators caused by CPB.

\section{Methods}

After approval of the institutional review board and after informed consent was obtained, patients were enrolled in the study protocol at the Lancisi hospital (Ancona, Italy). Inclusion criteria were age of 18 years or older and elective coronary artery bypass surgery. Exclusion criteria were the presence of cardiogenic pulmonary edema, emergency or urgent cases, preexisting chronic obstructive pulmonary disease, smoking history, major chest wall abnormalities, and enrollment in other studies.

All patients received diazepam $(0.15 \mathrm{mg} / \mathrm{kg})$, morphine $(0.1$ $\mathrm{mg} / \mathrm{kg})$, and scopolamine $(0.3 \mathrm{mg} / \mathrm{kg})$. Radial and pulmonary catheters were introduced. After tracheal intubation, lungs were ventilated with intermittent positive pressure ventilation. $\mathrm{V}_{\mathrm{T}}$, respiratory frequency, and fraction of inspired oxygen $\left(\mathrm{FIO}_{2}\right)$ were adjusted to maintain an arterial $\mathrm{PCO}_{2}$ of between 35 and $40 \mathrm{~mm} \mathrm{Hg}$ and an arterial oxygen saturation of greater than $95 \%$. Sternotomy and internal thoracic artery harvesting were performed in all patients. Heparin was administered at a dose of $3 \mathrm{mg} / \mathrm{kg}$ to achieve a target activated clotting time of 420 seconds or more. CPB was established and conducted at moderate hypothermia $\left(30^{\circ} \mathrm{C}\right)$. Mechanical ventilation was stopped after cardioplegic arrest by disconnecting the patient from the ventilator.

After weaning from $\mathrm{CPB}$, mechanical ventilation was restored after 1 to 2 minutes of manual ventilation $\left(\mathrm{FIO}_{2}, 0.5\right)$; patients were randomly assigned to a high- $\mathrm{V}_{\mathrm{T}} /$ low-PEEP (10-12 mL/kg measured body weight and 2-3 $\mathrm{cm} \mathrm{H}_{2} \mathrm{O}$, respectively) or low- $\mathrm{V}_{\mathrm{T}} /$ highPEEP $\left(8 \mathrm{~mL} / \mathrm{kg}\right.$ measured body weight and $10 \mathrm{~cm} \mathrm{H}_{2} \mathrm{O}$, respectively) group. In both ventilatory strategies, $\mathrm{FIO}_{2}$ was 0.5 , inspiratory/expiratory ratio was 1:2, and respiratory rate was 12 to 15 breaths/min. After chest closure, patients were transferred to the intensive care unit and ventilated, with the ventilatory pattern selected randomly. Sedation and muscle relaxation was maintained, and patients were kept in the supine position throughout the study period.

Protocol withdrawal occurred with any of the following a priori conditions: need for levels of dobutamine or dopamine of greater than $5 \mu \mathrm{g} \cdot \mathrm{kg}^{-1} \cdot \mathrm{min}^{-1}$, hemodynamically unstable condition with PEEP, or major cardiac arrhythmia. Patients were extubated when hemodynamically stable, fully rewarmed, awake, without surgical bleeding, and with optimal blood gases.

BAL fluid and blood samples were taken before sternotomy (time 0), immediately after protamine administration and CPB separation (time 1), and 6 hours after mechanical ventilation was restored (time 2).
TABLE 1. Prerandomization patient characteristics

\begin{tabular}{lcc}
\hline & Low $\mathbf{V}_{\mathbf{T}} / \mathbf{h i g h}$ PEEP & High $\mathbf{V}_{\mathbf{T}} /$ low PEEP \\
\hline Male/female sex, $\mathrm{n}$ & $12 / 8$ & $15 / 5$ \\
Age, $\mathrm{y}$ & $66.5 \pm 9.8$ & $68.7 \pm 7.4$ \\
Body surface area, $\mathrm{m}$ & $1.95 \pm 0.21$ & $1.88 \pm 0.13$ \\
Left ventricular ejection & & \\
$\quad$ fraction, $\%$ & $68 \pm 25$ & $55 \pm 15$ \\
Diabetes & $6(30 \%)$ & $5(25 \%)$ \\
Hypertension & $16(80 \%)$ & $15(75 \%)$ \\
Hyperlipidemia & $12(60 \%)$ & $14(70 \%)$ \\
Peripheral vascular disease & $4(20 \%)$ & $5(25 \%)$ \\
CPB time, min & $91 \pm 19$ & $83 \pm 25$ \\
CPB temperature, ${ }^{\circ} \mathrm{C}$ & $30 \pm 2$ & $30 \pm 2$ \\
Crossclamp time, min & $60 \pm 17$ & $50 \pm 20$
\end{tabular}

Data are presented as means \pm standard deviation. $V_{T}$, Tidal volume; $P E E P$, positive end-expiratory pressure.

BAL was performed by wedging the tip of a fiberoptic bronchoscope in a segmental airway of the right lower lobe and injecting 2 aliquots of 40 to $50 \mathrm{~mL}$ of sterile isotonic saline. Lavage with a third aliquot was performed if there was less than 30 to $40 \mathrm{~mL}$ of recovered fluid from the first $100 \mathrm{~mL}$. The first aliquot was discarded, and the remaining BAL fluid was rapidly filtered through sterile gauze and then spun at $4{ }^{\circ} \mathrm{C}$ and $400 \mathrm{~g}$ for 15 minutes. The supernatant was centrifuged at $80,000 \mathrm{~g}$ for $30 \mathrm{~min}$ utes at $4^{\circ} \mathrm{C}$ to remove the surfactant-rich fraction and than concentrated 10-fold on a 5000-d molecular weight cutoff filter (Amicon, Beverly) under nitrogen. The concentrated supernatant was than frozen at $-80^{\circ} \mathrm{C}$. Blood samples $(20 \mathrm{~mL})$ obtained from a central venous line were placed in a specimen tube containing heparin and centrifuged at $1500 \mathrm{~g}$ for 10 minutes, and then the plasma was aspirated and stored at $-80^{\circ} \mathrm{C}$. All cytokine determinations on the BAL fluid and plasma were carried out in duplicate in Turin, with the technician blinded to ventilation strategy using a solid-phase enzyme-linked immunoabsorbent assay method (Immunotech). ${ }^{5}$

The values for the cytokine concentrations were not normally distributed. Therefore $\log _{10}$ transformations were performed to normalize the data to permit the application of parametric statistics.

On the basis of previous data, ${ }^{5}$ the trial was designed to enroll 40 patients to demonstrate a $50 \%$ reduction in inflammatory mediators after CPB between high $\mathrm{V}_{\mathrm{T}}$ /low PEEP and low $\mathrm{V}_{\mathrm{T}}$ /high PEEP $(\alpha=.05$, power $=0.8)$. Repeated-measures analysis of variance with the Bonferroni method was used to evaluate differences over time of cytokine values within each group. The Fisher exact test for categorical variables, the $t$ test with unequal variance for continuous variables, and the Mann-Whitney rank sum test for ordinal variables were used to evaluate differences between the 2 groups. All tests of significance were 2-tailed.

\section{Results}

Baseline anthropometric characteristics and clinical parameters were similar in the 2 groups (Table 1). There were neither deaths nor major complications in either group, and no patient had to undergo reoperation or be readmitted after 
TABLE 2. Physiologic parameters measured 6 hours after mechanical ventilation was restored

\begin{tabular}{lcc}
\hline & Low $\mathbf{V}_{\mathrm{T}}$ /high PEEP & High $\mathbf{V}_{\mathrm{T}}$ /low PEEP \\
\hline $\mathrm{V}_{\mathrm{T}}, \mathrm{mL} / \mathrm{kg}$ & $6.8 \pm 1.2$ & $10.9 \pm 1.5^{*}$ \\
$\mathrm{PEEP}, \mathrm{cm} \mathrm{H}_{2} \mathrm{O}$ & $9.1 \pm 3.5$ & $2.1 \pm 2.2^{*}$ \\
End-inspiratory plateau & & \\
$\quad$ pressure, $\mathrm{cm} \mathrm{H} \mathrm{H}_{2} \mathrm{O}$ & $18.4 \pm 3.5$ & $25.6 \pm 4.1^{*}$ \\
$\mathrm{Minute}^{*}$ ventilation, L/min & $8.1 \pm 1.2$ & $12.2 \pm 1.7^{*}$ \\
$\mathrm{PaO}_{2}, \mathrm{~mm} \mathrm{Hg}$ & $162 \pm 60$ & $172 \pm 47$ \\
$\mathrm{PacO}_{2}, \mathrm{~mm} \mathrm{Hg}$ & $42 \pm 9$ & $33 \pm 5^{*}$ \\
Arterial pH $^{\text {Pulmonary arterial wedge }}$ & $7.36 \pm 0.08$ & $7.45 \pm 0.06^{*}$ \\
$\quad$ pressure & $11.7 \pm 6$ & $10.3 \pm 4$ \\
Right atrial pressure, mm $\mathrm{Hg}$ & $9.4 \pm 3.50$ & $7.7 \pm 3.6$ \\
Mean arterial pressure, & & \\
mm Hg & $84.1 \pm 12.0$ & $72.7 \pm 3.3^{*}$ \\
\hline
\end{tabular}

Data are presented as means \pm standard deviation. $V_{T}$, Tidal volume; $P E E P$, positive end-expiratory pressure; $P_{a O_{2}}$ partial pressure of oxygen, arterial; $\mathrm{PaCO}_{2}$, partial pressure of carbon dioxide, arterial. $* P<.001$.

intensive care unit discharge. Postoperatively, all patients were in hemodynamically stable condition, no patients had postoperative low cardiac output requiring dobutamine or dopamine of greater than $5 \mu \mathrm{g} \cdot \mathrm{kg}^{-1} \cdot \min ^{-1}$ or intraaortic balloon pump counterpulsation, and all patients tolerated postoperative PEEP; therefore no patients had to be excluded from the study.
Values of ventilator settings and arterial blood gases 6 hours after re-establishing mechanical ventilation are shown in Table 2. Arterial $\mathrm{Po}_{2}$ did not differ between groups, but patients in the low- $\mathrm{V}_{\mathrm{T}}$ /high-PEEP group showed values of arterial pressure of carbon dioxide higher and arterial $\mathrm{pH}$ lower $(P<.001)$ than those observed in patients in the high- $\mathrm{V}_{\mathrm{T}}$ /low-PEEP group.

Concentrations of inflammatory mediators in the BAL fluid and plasma at time 0 were low and significantly increased at time 1 in both groups. Concentrations of interleukin (IL) 6 and IL-8 in the BAL fluid and plasma further increased after 6 hours of mechanical ventilation with high $\mathrm{V}_{\mathrm{T}}$ /low PEEP, although it did not change after 6 hours of mechanical ventilation with low $\mathrm{V}_{\mathrm{T}}$ /high PEEP. Concentrations of IL- 6 and IL- 8 in the BAL fluid and in the plasma after 6 hours of mechanical ventilation were higher in patients ventilated with high $\mathrm{V}_{\mathrm{T}}$ /low PEEP than in patients ventilated with low $\mathrm{V}_{\mathrm{T}}$ /high PEEP; BAL and plasma concentrations of IL- 6 and IL- 8 at time 0 and time 1 did not differ between groups (Figures 1 and 2).

\section{Discussion}

Patients undergoing cardiac surgery are exposed to numerous possible triggers of a systemic inflammatory response. Interventions aimed to attenuate the CPB-induced inflammatory response result in improvement of physiologic parameters and clinical outcome. ${ }^{1}$ The present study indicates

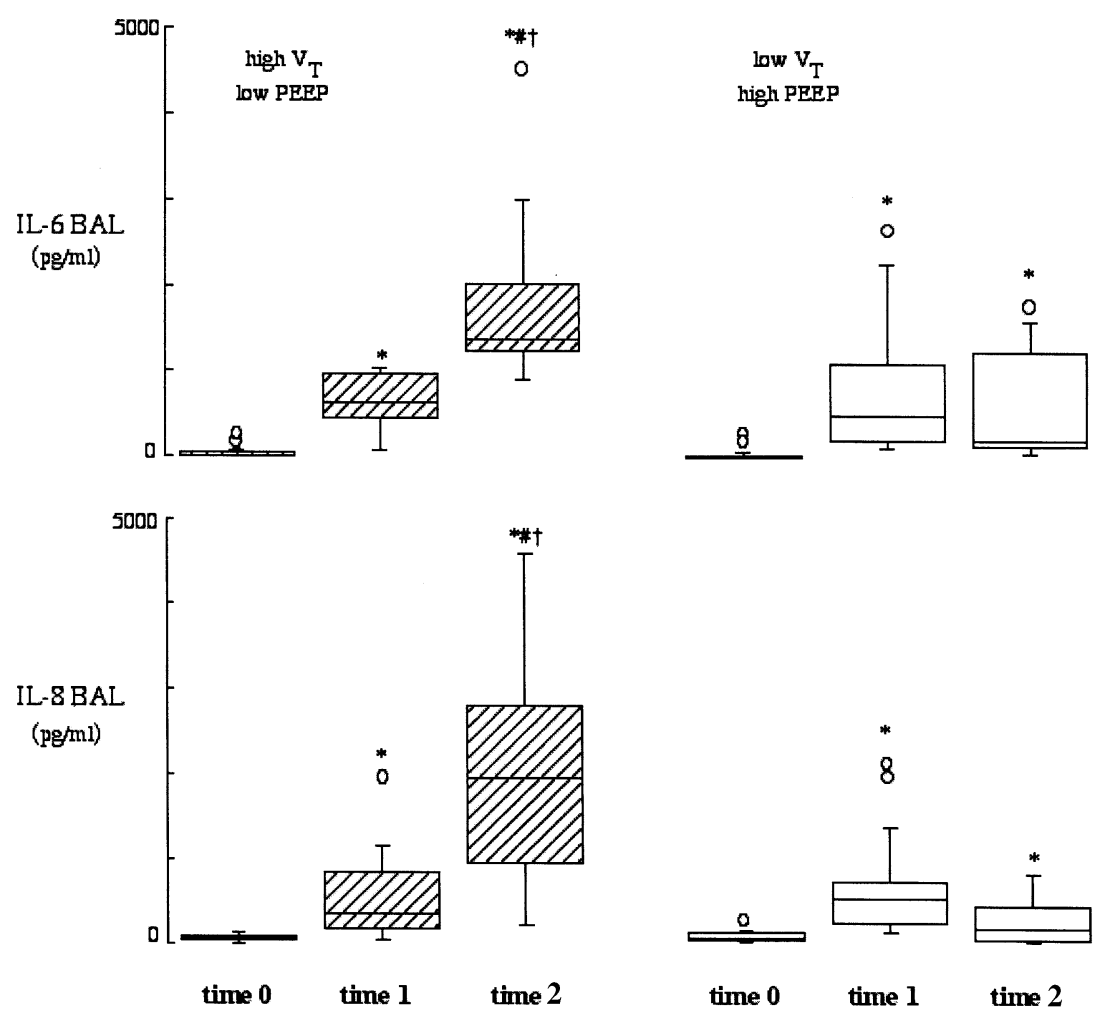

Figure 1. Effect of different ventilatory strategies on IL-6 and IL-8 concentrations in BAL fluid before sternotomy (time 0 ), after CPB (time 1), and 6 hours after re-establishment of mechanical ventilation (time 2). Graphics are clustered box plots summarizing the median and quartiles. ${ }^{*} P<.01$ versus time $0 ; \# P<.01$ versus time $1 ;+P<.01$, high $V_{T} /$ low PEEP versus low $\mathrm{V}_{\mathrm{T}}$ /high PEEP. 


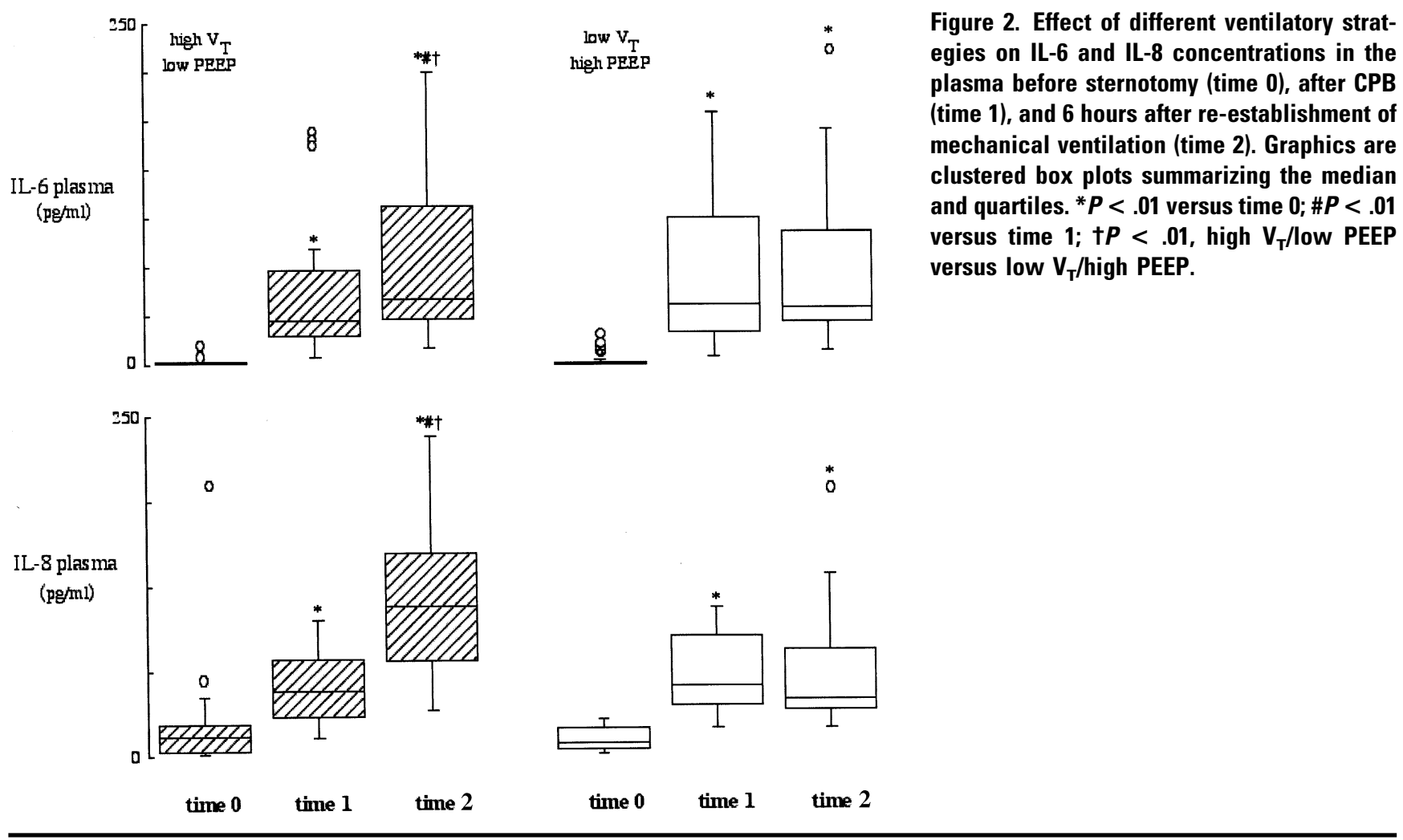

that although conventional mechanical ventilation further increases the pulmonary and systemic concentration of inflammatory mediators consequent to $\mathrm{CPB}$, use of lower $\mathrm{V}_{\mathrm{T}}$ and higher PEEP might attenuate the pulmonary and systemic inflammatory response. These data first demonstrate that mechanical ventilation could be a cofactor able to influence the inflammatory response after cardiac surgery.

Mechanical ventilation is essential to maintain adequate ventilation and systemic oxygenation in patients recovering from cardiac surgery and CPB. Recent experimental studies have demonstrated that mechanical ventilation can induce morphologic and functional alteration of the lungs caused by stress failure generated by overinflation of some alveolar regions and by shear stress generated by continuous alveolar opening and closing. ${ }^{4,5}$ Explanation of these results relies on the observation that, in a nonuniformly injured lung, mechanical ventilation might generate stress failure and shear forces that amplify pressure in some alveolar regions as high as $140 \mathrm{~cm} \mathrm{H}_{2} \mathrm{O}$, even though pressure applied at the airway opening amounts only to $30 \mathrm{~cm} \mathrm{H}_{2} \mathrm{O}$. ${ }^{9}$ These forces might initiate, worsen, or both a pulmonary and systemic inflammatory response $\mathrm{s}^{4,5}$ and contribute to the development of multiple organ failure. ${ }^{10,11}$ A recent multicenter trial including patients with acute respiratory distress syndrome (ARDS) compared traditional ventilation with a $\mathrm{V}_{\mathrm{T}}$ of 12 $\mathrm{mL} / \mathrm{kg}$ with ventilation with a $\mathrm{V}_{\mathrm{T}}$ of $6 \mathrm{~mL} / \mathrm{kg}$; mortality was significantly lower in patients treated with the lower $\mathrm{V}_{\mathrm{T}}{ }^{7}$
The incidence of ARDS after elective cardiac surgery is as low as $1 \%$ to $3 \%$, whereas impairment of lung function and oxygenation are found in $20 \%$ to $90 \%$ of patients who have undergone $\mathrm{CPB}$ and have been recognized as an important cause of postoperative morbidity. ${ }^{12}$ At time 1, the $\mathrm{PaO}_{2} / \mathrm{FIO}_{2}$ ratio was $290 \pm 116$ and $264 \pm 120$ and the pulmonary arterial wedge pressure was $10.3 \pm 4$ and $11.7 \pm 6$ in the high- $\mathrm{V}_{\mathrm{T}} /$ low-PEEP and low- $\mathrm{V}_{\mathrm{T}}$ /high-PEEP groups, respectively; none of the patients had bilateral infiltrates on standard chest radiography. Under these circumstances, none of the patients included in the present study had ARDS. ${ }^{13}$

Similar to patients after abdominal surgery, the lungs of patients after CPB are asymmetric along the vertical axis, with relatively normal regions located in the nondependent zones, areas of partially collapsed lung and/or alveolar filling located in the middle zones, and area of pulmonary consolidation located in the most dependent regions. ${ }^{14,15}$ Under these circumstances, mechanical ventilation might stress the lungs because of recruitment-derecruitment of atelectatic alveoli and hyperinflation of normal alveoli when inappropriate levels of PEEP are used, when the large part of the inflating volume is distributed to the normal lung regions, or both. ${ }^{16}$ However, Wrigge and coworkers ${ }^{17,18}$ found that in patients after major noncardiac surgery, mechanical ventilation with a $\mathrm{V}_{\mathrm{T}}$ of 0.8 to $1.2 \mathrm{~L}$ and zero PEEP induces no relevant increase in inflammatory mediators. We found that pulmonary and plasmatic concentrations of in- 
flammatory mediators increased after 6 hours of mechanical ventilation only in patients ventilated with high $\mathrm{V}_{\mathrm{T}} /$ low PEEP, whereas these values did not change in patients ventilated with low $\mathrm{V}_{\mathrm{T}} /$ high PEEP. These results might be explained by the ischemia of the lung caused by the cessation of pulmonary arterial flow after aortic crossclamping. This might lead to pulmonary endothelial dysfunction, ${ }^{19}$ platelet-neutrophil accumulation, ${ }^{20}$ increase in myeloperoxidase activity, ${ }^{21}$ and activation of adhesion molecules. ${ }^{22}$ Data of the present investigation therefore support the concept that stress caused by mechanical ventilation represents a relevant inflammatory stimulus only in the presence of a previous inflammatory stimulus represented in our patients by CPB. Preliminary data from Wrigge and coworkers ${ }^{23}$ indicate that after cardiac surgery, ventilation with a lower $\mathrm{V}_{\mathrm{T}}$ decreases pulmonary inflammatory mediators, particularly in patients in whom CPB induced a more relevant increase in the pulmonary concentration of inflammatory mediators. Recently, Koner and colleagues ${ }^{24}$ found no difference in systemic cytokine release in patients after cardiac surgery ventilated with a $\mathrm{V}_{\mathrm{T}}$ of $6 \mathrm{~mL} / \mathrm{kg}$ and PEEP of $5 \mathrm{~cm}$ $\mathrm{H}_{2} \mathrm{O}$ compared with those ventilated with a $\mathrm{V}_{\mathrm{T}}$ of $10 \mathrm{~mL} / \mathrm{kg}$ with and without PEEP at $5 \mathrm{~cm} \mathrm{H}_{2} \mathrm{O}$. Unfortunately, in their protocol the last blood sample for IL- 6 and TNF- $\alpha$ measurements was taken only 2 hours after the end of CPB, while the inflammatory reaction was still increasing. A protective effect of low $\mathrm{V}_{\mathrm{T}}$ /high PEEP in our study was observed 6 hours after the end of CPB, which is the mechanical ventilation time usually necessary for patients who have undergone uncomplicated cardiac surgery.

Several studies have found that post-CPB inflammatory reactions influence lungs function. Kotami and associates ${ }^{25}$ found that the pulmonary concentration of IL-8 after disconnection from CPB was significantly correlated to values of arterial oxygenation and intrapulmonary shunt at the end of surgical intervention. Holmes and coworkers ${ }^{26}$ correlated postoperative clinical outcome with inflammatory mediators release and found that the length of mechanical ventilation after surgical intervention was longer in patients with a larger magnitude of inflammation after CPB. Consistently, Rothenburger and colleagues ${ }^{27}$ observed that the postoperative concentration of IL- 8 was higher in patients ventilated for more than 24 hours than in patients ventilated for less than 24 hours.

Adoption of a smaller $\mathrm{V}_{\mathrm{T}}$ to protect the lung from lung stretch might potentially lead to an increase of arterial $\mathrm{PCO}_{2}$ and respiratory acidosis. ${ }^{5-7}$ In our study patients ventilated for 6 hours with low $\mathrm{V}_{\mathrm{T}}$ /high PEEP had values of arterial $\mathrm{PCO}_{2}$ of $42 \pm 9 \mathrm{~mm} \mathrm{Hg}$ and an arterial $\mathrm{pH}$ of $7.36 \pm 0.08$. Recent data suggest that hypercapnic acidosis is highly protective in experimental models of pulmonary ${ }^{28}$ and myocardial $^{29}$ ischemia-reperfusion injury.
Our study was not designed to produce significant clinical outcome data. The effect of this observation is limited by the unblinded data collection procedure and needs to be confirmed in appropriately designed future trails.

Several factors are able to influence inflammatory response measured after CPB. These factors can be synthesized preoperatively (patient characteristics and preoperative inflammatory state), intraoperatively (surgical trauma, time on CPB, aortic crossclamp time, type of CPB equipment, anesthesia management, and use of anti-inflammatory drugs), and postoperatively (use of anti-inflammatory drugs, postoperative low cardiac output syndrome, and postoperative infections). ${ }^{1}$ Table 1 shows that there are no significant preoperative difference between the groups; surgical intervention was performed in all patients through a sternotomy with similar CPB equipment and anesthesia management. No patient received antifibrinolytic drugs at any time, had low cardiac output syndrome, had to undergo reoperation for bleeding, or showed signs of infection during the study period. Nevertheless, our trial was a proof-of-concept study to determine whether ventilatory strategy could affect BAL and serum cytokine levels in patients undergoing cardiac surgery and $\mathrm{CPB}$; future clinical trials with larger sample sizes and protocols designed to standardized clinical cointerventions are required to confirm our observation and evaluate the effects of ventilatory strategies on clinical end points.

\section{References}

1. Paparella D, Yau TM, Young E. Cardiopulmonary bypass induced inflammation: pathophysiology and treatment. An update. Eur J Cardiothorac Surg. 2002;21:232-44.

2. Esteban A, Anzueto A, Frutos F, et al. Characteristics and outcomes in adult patients receiving mechanical ventilation: a 28 -day international study. JAMA. 2002;287:345-55.

3. Tremblay L, Valenza F, Ribeiro SP, Li J, Slutsky AS. Injurious ventilatory strategies increase cytokines and c-fos m-RNA expression in an isolated rat lung model. J Clin Invest. 1997;99:944-52.

4. Chiumello D, Pristine G, Slutsky AS. Mechanical ventilation affects local and systemic cytokines in an animal model of acute respiratory distress syndrome. Am J Respir Crit Care Med. 1999;160:109-16.

5. Ranieri VM, Suter PM, Tortorella C, et al. Effects of mechanical ventilation on inflammatory mediators in patients with acute respiratory distress syndrome. A randomized controlled trial. JAMA. 1999; 282:54-61.

6. The Acute Respiratory Distress Syndrome Network. Ventilation with lower tidal volumes as compared with traditional tidal volumes for acute lung injury and the acute respiratory distress syndrome. $N$ Engl J Med. 2000;342:1301-8.

7. Amato MB, Barbas CS, Medeiros DM, et al. Effect of a protectiveventilation strategy on mortality in the acute respiratory distress syndrome. N Engl J Med. 1998;338:347-54.

8. Brower RG, Lanken PN, MacIntyre N, et al. Higher versus lower positive end-expiratory pressures in patients with the acute respiratory distress syndrome. N Engl J Med. 2004;351:327-36.

9. Mead J, Takishima T, Leith D. Stress distribution in lungs: a model of pulmonary elasticity. J Appl Physiol. 1970;28:596-608.

10. Ranieri VM, Giunta F, Suter PM, Slutsky AS. Mechanical ventilation as a mediator of multisystem organ failure in acute respiratory distress syndrome. JAMA. 2000;284:43-4. 
11. Imai $\mathrm{Y}$, Parodo J, Kajikawa $\mathrm{O}$, et al. Injurious mechanical ventilation and end-organ epithelial cell apoptosis and organ dysfunction in an experimental model of acute respiratory distress syndrome. JAMA. 2003;289:2104-12.

12. Asimakopoulos G, Smith PL, Ratnatunga CP, Taylor KM. Lung injury and acute respiratory distress syndrome after cardiopulmonary bypass. Ann Thorac Surg. 1999;68:1107-15.

13. Bernard GR, Artigas A, Brigham KL, et al. The American-European Consensus Conference on ARDS. Definitions, mechanisms, relevant outcomes, and clinical trial coordination. Am J Respir Crit Care Med. 1994;149:818-24.

14. Hachenberg T, Tenling A, Nystrom SO, Tyden H, Hedenstierna G. Ventilation-perfusion inequality in patients undergoing cardiac surgery. Anesthesiology. 1993;80:509-19.

15. Hachenberg T, Brussel T, Roos N, et al. Gas exchange impairment and pulmonary densities after cardiac surgery. Acta Anaesthesiol Scand. 1992;36:800-5.

16. Gattinoni L, D'Andrea L, Pelosi P, et al. Regional effects and mechanism of positive end-expiratory pressure in early adult respiratory distress syndrome. JAMA. 1993;269:2122-7.

17. Wrigge H, Zinserling J, Stuber F, et al. Effects of mechanical ventilation on release of cytokines into systemic circulation in patients with normal pulmonary function. Anesthesiology. 2000;93:1413-7.

18. Wrigge $\mathrm{H}$, Uhlig $\mathrm{U}$, Zinserling $\mathrm{J}$, et al. The effects of different ventilatory settings on pulmonary and systemic inflammatory responses during major surgery. Anesth Analg. 2004;98:775-81.

19. Chai PJ, Williamson JA, Lodge AJ, et al. Effects of ischemia on pulmonary dysfunction after cardiopulmonary bypass. Ann Thorac Surg. 1999;67:731-5.

20. Brix-Christiansen V, Tonnesen E, Hjortdal VE, et al. Neutrophils and platelet accumulate in the heart, lungs, and kidneys after cardiopulmonary bypass in neonatal piglets. Crit Care Med. 2002;30:670-6.
21. Bando K, Pillai R, Cameron D, et al. Leukocyte depletion ameliorates free radical-mediated lung injury after cardiopulmonary bypass. $J$ Thorac Cardiovasc Surg. 1990;99:873-7.

22. Friedman M, Wang SY, Sellke FW, Cohn WE, Weintraub RM, Johnson RG. Neutrophil adhesion blockade with NPC 15669 decreases pulmonary injury after total cardiopulmonary bypass. J Thorac Cardiovasc Surg. 1996;111:460-8.

23. Wrigge $H$, Uhlig $U$, Zinserling $\mathbf{J}$, et al. Inflammatory effects of lower tidal volume ventilation after cardiac surgery. Intensive Care Med. 2003;29(suppl):S82.

24. Koner O, Celebi S, Balci H, Cetin G, Karaoglu K, Cakar N. Effects of protective and conventional mechanical ventilation on pulmonary function and systemic cytokine release after cardiopulmonary bypass. Intensive Care Med. 2004;30:620-6.

25. Kotani N, Hashimoto H, Sessler DI, et al. Neutrophil number and interleukin-8 and elastase concentrations in bronchoalveolar lavage fluid correlate with decreased arterial oxygenation after cardiopulmonary bypass. Anesth Analg. 2000;90:1046-51.

26. Holmes JH, Connolly NC, Paull DL, et al. Magnitude of the inflammatory response to cardiopulmonary bypass and its relation to adverse clinical outcomes. Inflamm Res. 2002;51:579-86.

27. Rothenburger M, Soeparwata R, Deng MC, et al. The impact of anti-endotoxin core antibodies on endotoxin and cytokine release and ventilation time after cardiac surgery. J Am Coll Cardiol. 2001;38: 124-30.

28. Shibata K, Cregg N, Engelberts D, et al. Hypercapnic acidosis may attenuate acute lung injury by inhibition of endogenous xanthine oxidase. Am J Respir Crit Care Med. 1998;158:1578-84.

29. Nomura F, Aoki M, Forbess JM, et al. Effects of hypercarbic acidotic reperfusion on recovery of myocardial function after cardioplegic ischemia in neonatal lambs. Circulation. 1994;90:321-7. 